\title{
Effect of pioglitazone on neuropathic pain and spinal expression of TLR-4 and cytokines
}

\author{
HONGBIN JIA, SHUANGSHUANG XU, QINGZHEN LIU, JIAN LIU, \\ JIANGUO XU, WEIYAN LI, YI JIN and QING JI
}

Department of Anesthesiology, Jinling Hospital, School of Medicine, Nanjing University, Nanjing, Jiangsu 210002, P.R. China

Received December 18, 2014; Accepted January 8, 2015

DOI: $10.3892 /$ etm. 2016.3643

\begin{abstract}
The molecular mechanisms underlying neuropathic pain have yet to be elucidated. The present study aimed to examine the modulation of neuroimmune activation in the spinal cord by the synthetic peroxisome proliferator-activated receptor gamma (PPAR- $\gamma$ ) agonist, pioglitazone (Pio), in a rat model of neuropathic pain induced by chronic constriction injury (CCI). Rats were randomly assigned into four groups: Sham surgery with vehicle, chronic constriction injury with vehicle or Pio $(10 \mathrm{mg} / \mathrm{kg})$, and chronic constriction injury with Pio and a PPAR- $\gamma$ antagonist GW9662 (2 mg/kg). Pio or vehicle was administered $1 \mathrm{~h}$ prior to the surgery and continued daily until day 7 post-surgery. Paw pressure threshold was measured prior to surgery and on days 0,1 , 3 and 7 post-surgery. Microglia activation markers macrophage antigen complex-1, the mRNA expression levels of tumor necrosis factor $\alpha$ and interleukin-1 $\beta$, and the mRNA expression levels of toll like receptor (TLR-4) in the lumbar spinal cord were determined. Administration of Pio resulted in the prominent attenuation of mechanical hyperalgesia. In addition, Pio was able to significantly inhibit neuroimmune activation characterized by glial activation, the production of cytokines and expression levels of TLR-4. Concurrent administration of a PPAR- $\gamma$ antagonist, GW9662, reversed the effects of Pio. The antihyperalgesic effect of administration of Pio in rats receiving CCI may, in part, be attributed to the inhibition of neuroimmune activation associated with the sustaining of neuropathic pain.
\end{abstract}

Correspondence to: Professor Qing Ji, Department of Anesthesiology, Jinling Hospital, School of Medicine, Nanjing University, 305 East Zhongshan Road, Nanjing, Jiangsu 210002, P.R. China

E-mail: jzwrite@163.com

Key words: pioglitazone, neuropathic pain, Mac-1, inflammatory cytokines, toll-like receptor 4 , peroxisome proliferator activated receptor gamma

\section{Introduction}

Neuropathic pain is an intractable affliction caused as a result of various forms of damage to the nervous system. The mechanisms underlying the development of neuropathic pain are yet to be elucidated. Several previous studies using animal models have suggested candidates that may be therapeutic targets for the reduction of neuropathic pain. However, there are currently no good pharmacotherapies for neuropathic pain (1). Substantial evidence has demonstrated that central neuroimmune activation and neuroinflammation have crucial roles in the generation and maintenance of chronic pain (2). Subsequent to nerve injury, microglia in the spinal cord become activated and pro-inflammatory cytokines are released, including tumor necrosis factor (TNF)- $\alpha$ and interleukin (IL)-1 $\beta$. In addition, the activation of glia is accompanied by the release of chemical mediators, including substance $\mathrm{P}$, inflammatory cytokines and chemokines, which subsequently enhance the activation of spinal glia (3-7). The suppression of microglia activity is has been explored as a potential therapy for a number of central nervous system (CNS) inflammatory diseases and neuropathic pain (8).

Toll like receptors (TLRs) are transmembrane signaling molecules that participate in innate immune recognition (9). Previous evidence has suggested that TLR-4 is expressed by microglial cells in the CNS, and that the activation of these cells is associated with the release of pro-inflammatory cytokines (10). Thus, the inhibition of TLR-4 may reduce inflammatory responses and ameliorate the pain experienced after nerve-injury.

Peroxisome proliferator-activated receptor gamma (PPAR- $\gamma$ ) is transcription factor that belongs to the nuclear hormone receptor family. PPAR- $\gamma$ agonists are currently employed clinically for the management of type II diabetes mellitus. Furthermore, previous studies have shown that PPAR- $\gamma$ has the potential to ameliorate the symptoms of nervous system-associated disorders, such as spinal cord injury, amyotrophic lateral sclerosis, allergic encephalomyelitis, Parkinson's disease, cerebral hemorrhage and Alzheimer's disease (11-16). However, studies concerning the underlying mechanism of PPAR- $\gamma$ agonists on neuroimmune activation associated with neuropathic pain, are limited. Pioglitazone (Pio) is a promising PPAR $-\gamma$ antagonist, which may penetrate the blood-brain barrier to exert its actions on the CNS (17). 
Therefore, using a rat model of chronic constriction injury, the current study was conducted to evaluate the role of orally administered Pio on pain behaviors, inflammatory cytokines, glial activation and the expression of TLR-4. The current study also aimed to determine whether the analgesic effect of Pio was associated with its impact on the expression of cytokines and TLR-4, as well as glial activation markers involved in neuroimmune activation.

\section{Materials and methods}

Experimental animals and procedures. Male Sprague-Dawley rats (age, 45-50 days) weighing between 200 and $250 \mathrm{~g}$ were housed in an approved facility and maintained at $20-25^{\circ} \mathrm{C}$, $50 \%$ humidity and under a 12-h dark:light cycle, with food and water available ad libitum. All animal experiments were performed in accordance with the National Institutes of Health Guide regarding the care and use of animals for experimental procedures. Efforts were made to limit distress and to use the minimum number of rats necessary to achieve statistical significance. The experimental protocol was reviewed and approved by the Institutional Animal Care Committee of Jinling Hospital (Nanjing, China).

Surgery to produce chronic constriction injury (CCI) was first described by Bennett and Xie (18). Subsequent to the administration of urethane anesthesia $(1 \mathrm{~g} / \mathrm{kg}$, ip) the right sciatic nerve was exposed, and proximal to the trifurcation, $\sim 7 \mathrm{~mm}$ of the common sciatic nerve was freed from the adherent tissue. Four 4-0 chromic gut sutures, were tied around the nerve at intervals of $\sim 1 \mathrm{~mm}$, and ligatures were secured loosely to ensure that, on visual inspection, blood flow was not obstructed. The left sciatic nerve was used as a control, and was exposed yet not ligated, whereas the surgical incision was sutured and postsurgical recuperation was monitored daily, and the rats recovered uneventfully. Particular attention was applied to prevent infection, thus minimizing the influence of inflammation. Rats were randomized into four equal groups ( $n=8$ per group) as follows: i) Sham-operation with vehicle $(0.5 \%$ carboxymethyl cellulose or Pio; sham group); ii) chronic constriction injury with $2 \mathrm{ml} / \mathrm{kg}$ vehicle (vehicle group) or iii) $10 \mathrm{mg} / \mathrm{kg}$ Pio (Pio group); and iv) chronic constriction injury with coadministration of $10 \mathrm{mg} / \mathrm{kg}$ Pio and $2 \mathrm{mg} / \mathrm{kg}$ GW9662 (a PPAR- $\gamma$ antagonist) administered by intraperitoneal (i.p.) injection (Pio $+\mathrm{GW}$ group). The vehicle solution [0.5\% CMC or Pio (Medical and Pharmacological Company of Hengrui, China) was orally administered $1 \mathrm{~h}$ prior to surgery and continued daily to day 21 post-surgery.

\section{Behavioral assessments}

Mechanical hyperalgesia. Paw withdrawal mechanical threshold (PWMT) was determined by applying a von Frey hair filament (Stoelting Co., Chicago, IL, USA) to the hind paw until a positive indicator of pain behavior was elicited (19). Evaluation thresholds were as follows: The mid-plantar paw was assessed in the area of the sciatic nerve, avoiding the footpads. The von Frey filaments with logarithmically incremental stiffness (0.4-15.1 g) were applied serially to the paw via the up-down method. The hairs were presented in ascending order of strength, perpendicular to the plantar surface with sufficient force to cause slight bending against the paw, and were held for 6-8 sec. A positive response was recorded if the paw was sharply withdrawn. Flinching immediately upon removal of the hair was also considered a positive response. A $15.1 \mathrm{~g}$ hair was selected as the upper limit for testing. If there was no response at $15.1 \mathrm{~g}$ pressure, rats were assigned the upper limit value. A bending force able to evoke $50 \%$ of the paw withdrawal occurrence was set as the PWMT.

Cold allodynia. Behavioral indicators of cold allodynia were identified by immersing the tails of rats in cold water $\left(4^{\circ} \mathrm{C}\right)$. As previously described (20), each animal was restrained in a plastic holder and its tail was allowed to hang over the edge to facilitate the application of cold water stimuli. Following the immersion of the tail, the latency of an abrupt tail movement was measured, with a cut-off time of $15 \mathrm{sec}$. Tail immersion assessment was repeated five times at 5-min intervals. When calculating the average latency, the cut-off time was assigned to rats with normal responses (an absence of tail movement for $15 \mathrm{sec}$ ). Average latency was employed as a measure for the severity of cold allodynia; a shorter latency was interpreted as more severe cold allodynia.

Harvesting of tissue samples. Subsequent to the completion of the behavioral assessment on day 21 post-operation, rats were anesthetized with an overdose of sodium pentobarbital (70 mg/kg), the rat hearts were exposed by thoracotomy and intracardially perfused with $250 \mathrm{ml}$ cold saline. Rats were then sacrificed by decapitation. The lumbar spinal cord tissue proximal to the injury site was harvested and kept on ice. The dorsal aspect of the spinal cord was dissected from the ventral portion of the spinal cord. Following this, the samples were removed quickly and stored in liquid nitrogen for subsequent assays.

Reverse-transcription polymerase chain reaction (RT-PCR) for the determination of $I L-1 \beta$ and TNF- $\alpha$ mRNA expression levels. Total RNA was extracted with Tri Pure Isolation Reagent (Roche Diagnostics, Basel, Switzerland) and quantified by absorption at $260 \mathrm{~nm}$. RNA samples all had OD260/280 ratios of 1.8-2.0, indicating good quality. RT was performed using Reverse Transcription System (Promega Corp., Madison, WI, USA) according to the manufacturer's protocol. $\beta$-actin as normalization control. Primer sequences were as follows: IL-1 $\beta$ sense 5'-TGATGTTCCCATTAGACAGC-3' and antisense 5'-GAGGTGCTGATGTACCAGTT-3'; TNF- $\alpha$, sense 5'-CTC AGCCTCTTCTCCTTCCT-3' and antisense 5'-ATGGGC TCATACCAGGGCTT-3'; and $\beta$-actin, sense 5'-CTGGCC GGGACCTGACTGACTACCTC-3' and antisense 5'-AAA CAAATAAAGCCATGCCAATCTCA-3'. The $100 \mu 1$ reaction volume consisted of $2 \mu \mathrm{l}$ cDNA template (Promega Corporation, Madison, WI, USA), $1.5 \mathrm{mmol} / \mathrm{I} \mathrm{MgCl}_{2}, 2.5 \mathrm{U}$ Taq DNA polymerase, $100 \mu \mathrm{mol} / 1 \mathrm{dNTP}, 0.1 \mu \mathrm{mol} / 1$ primer and $1 \mathrm{X}$ Taq DNA polymerase magnesium-free buffer (Promega Corp.). Next, the reaction mixture was supplemented with two drops of mineral oil (Sigma-Aldrich; Merck Millipore, Darmstadt, Germany) and incubated in a thermocycler (Mini-Cycler PTC 150, MJ Research Inc., Hercules, CA, USA) programmed to initially denature at $95^{\circ} \mathrm{C}$ for $2 \mathrm{~min}$, then denature at $95^{\circ} \mathrm{C}$ for $1 \mathrm{~min}$, anneal at $60^{\circ} \mathrm{C}$ for $1 \mathrm{~min}$ and extend at $72^{\circ} \mathrm{C}$ for $2 \mathrm{~min}$ for a total of 30 cycles. The final cycle was followed by incubation at $72^{\circ} \mathrm{C}$ for $5 \mathrm{~min}$, and cooling to $4^{\circ} \mathrm{C}$. The PCR products 


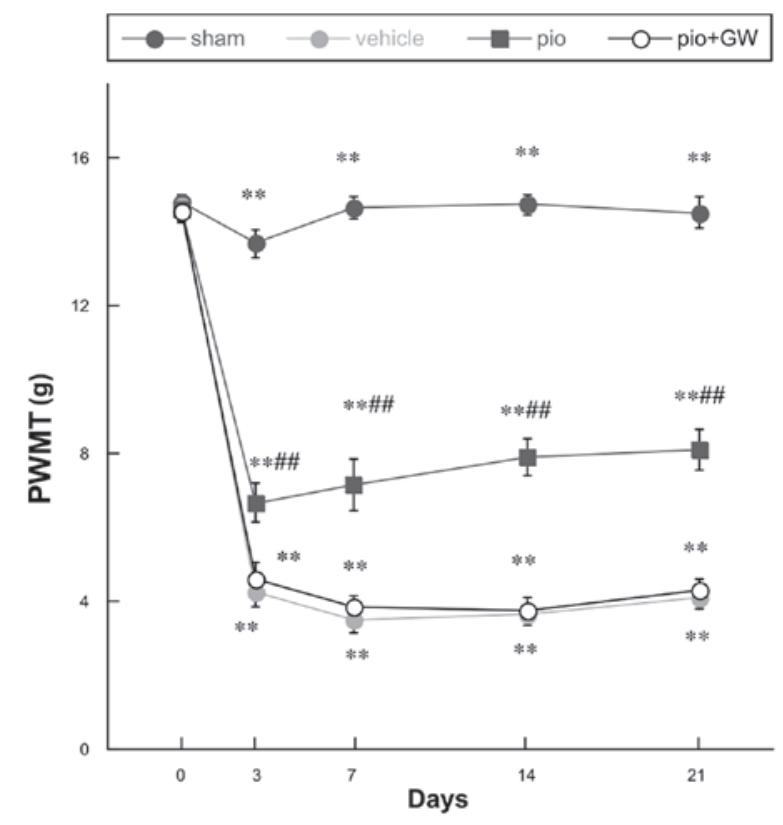

Figure 1. Changes in the PWMT prior to surgery and on days $0,3,7,14$ and 21 post-surgery. Compared with the sham group, there was a significant decrease in PWMT following chronic constriction injury ( $\left.{ }^{* *} \mathrm{P}<0.01\right)$ in each of the remaining groups. Pio administration attenuated the reduction in PWMT on postoperative days 3, 7,14 and 21 post-surgery compared with the vehicle group $\left({ }^{(\#)} \mathrm{P}<0.01\right)$, and this effect was reversed by co-administration with GW. PWMT, paw withdrawal mechanical threshold; Pio, pioglitazone; GW, GW9662.

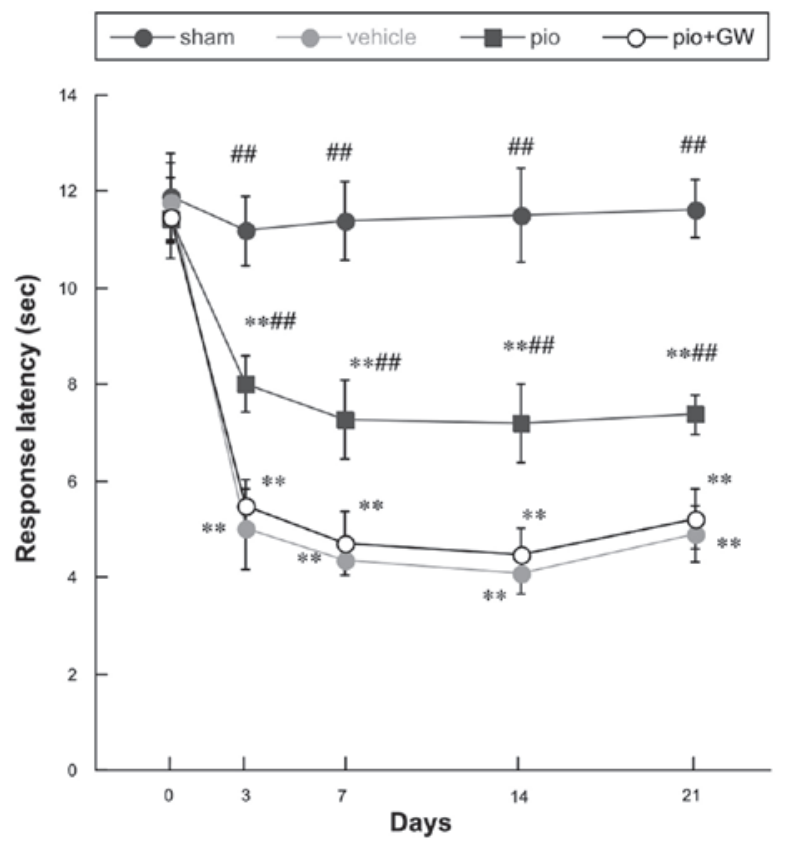

Figure 2. Changes in the response latency prior to surgery and on days $0,3,7$, 14 and 21 post-surgery. Compared with the sham group, there was a significant decrease in RL following chronic constriction injury ( $($ P* $<0.01)$. Pio administration attenuated the reduction in RL on postoperative days 3, 7, 14 and 21 post-surgery, compared with the vehicle group $\left({ }^{\# \prime} \mathrm{P}<0.01\right)$, and this effect was reversed by co-administration with GW. Pio, pioglitazone; GW, GW9662.

were 206 bp (IL-1 $\beta), 191$ bp (TNF- $\alpha$ ) and 650 bp ( $\beta$-actin), respectively. Subsequently, PCR products were electrophoresed on a $15 \mathrm{~g} / \mathrm{l}$ agarose gel stained with ethidium bromide. Digital images of the gel were captured and analyzed using Scion Image v. 4.03 software (Scion Corporation; Informer Technologies, Inc. Frederick, MD, USA). Values in each sample were normalized with $\beta$-actin.

RT-PCR for the determination of TLR4 mRNA expression levels. Total RNA was extracted with TriPure Isolation Reagent and quantified by absorption at $260 \mathrm{~nm}$. RT was performed using a Promega Reverse Transcription System according to the manufacturer's protocol. $\beta$-actin was used as an internal control for normalization. Primer sequences were as follows: TLR4, sense 5'-AGCTTTGGTCAGTTGGCTCT-3' and antisense 5'-CAGGATGACACCATTGAAGC-3'; and $\beta$-actin, sense 5'-CACCCGCGAGTACAACCTTC-3' and antisense 5'-CCCATACCCACCATCACACC-3'. Cycling conditions were as follows: $95^{\circ} \mathrm{C}$ for $2 \mathrm{~min}$, then $95^{\circ} \mathrm{C}$ for $1 \mathrm{~min}, 60^{\circ} \mathrm{C}$ for $1 \mathrm{~min}$ and $72^{\circ} \mathrm{C}$ for $2 \mathrm{~min}$ for 30 cycles. PCR amplification products were separated on an ethidium bromide-stained $1.5 \%$ agarose gel, and visualized by ultraviolet light. mRNA expression levels of TLR4 were calculated as a percentage of the mRNA expression levels of $\beta$-actin in the same tissue sample. Amplified bands showed the predicted sizes to be as follows: TLR4 $111 \mathrm{bp}$ and $\beta$-actin $149 \mathrm{bp}$.

Immunohistochemistry. Immunoreactivity analysis of the microglial activation marker Mac-1, or CR3/CD11b, was performed using immunohistochemistry. To suppress endogenous peroxidase activity, $4-\mu \mathrm{m}$ sections were treated with $0.3 \% \mathrm{H}_{2} \mathrm{O}_{2}$ in Tris-buffered saline (TBS) for $20 \mathrm{~min}$ at room temperature. Following this, sections were incubated overnight at $4^{\circ} \mathrm{C}$ with monoclonal mouse anti-Mac-1 (cat. no. 554980; 1:1,000; BD Pharmingen, San Diego, CA, USA) in TBS with $3 \%$ normal goat serum and $0.5 \%$ Triton-X-100. Subsequently, sections were incubated with biotin-conjugated goat anti-mouse (cat. no. 115-065-003; 1:400; Jackson ImmunoResearch, West Grove, PA) for $2 \mathrm{~h}$ at room temperature, incubated with an avidin-biotin complex solution (1:400; Vector Laboratories, Burlingame, CA, USA) for $1 \mathrm{~h}$ at room temperature, followed by staining with $0.5 \mathrm{mg} / \mathrm{ml} \mathrm{3,3'-diaminobenzidine} \mathrm{tetrahydro-}$ chloride (Sigma-Aldrich). Finally, sections were mounted on gelatin-coated slides, dried, dehydrated, and coverslipped with Permount. Staining was evaluated by light microscopy.

Statistical analysis. Values are expressed as means \pm standard error of the mean. For behavioral data, comparisons between groups were performed using repeated measures of analysis of variance (ANOVA). The effects of surgery and the administration of therapies on the cytokines and TLR- 4 were determined by one-way ANOVA followed by Bonferroni or Tamhane's T2 test based on equal variances assumed or otherwise. Data were analyzed using SPSS statistical software for Windows (version 13.0; SPSS, Inc., Chicago, IL, USA). P $<0.05$ was considered to indicate a statistically significant difference.

\section{Results}

Behavioral assessments. Mechanical hyperalgesia and cold allodynia were evidenced by PWMT (Fig. 1) and response latency (RL) (Fig. 2) findings. All rats demonstrated similar responsiveness to mechanical and cold stimuli prior to surgery 

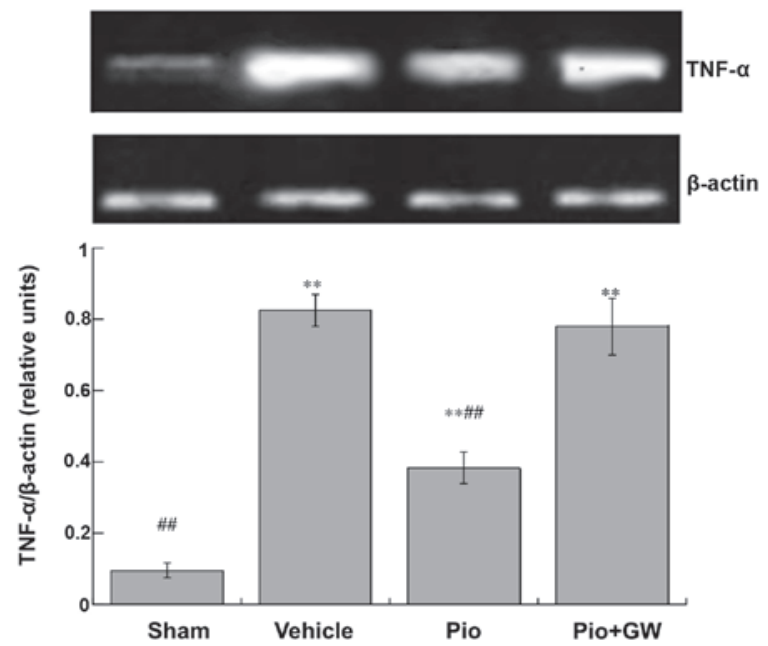

Figure 3. Spinal expression levels of TNF- $\alpha$ on day 21 post-surgery. Expression levels of TNF- $\alpha$ increased in rats following chronic constriction injury compared with the sham-operated rats $\left({ }^{* *} \mathrm{P}<0.01\right)$. Administration of Pio attenuated the increased expression levels of TNF- $\alpha$ compared with the vehicle group $\left({ }^{\# \#} \mathrm{P}<0.01\right)$, and this effect was reversed by co-administration with GW. TNF, tumor necrosis factor; Pio, pioglitazone; GW, GW9662.
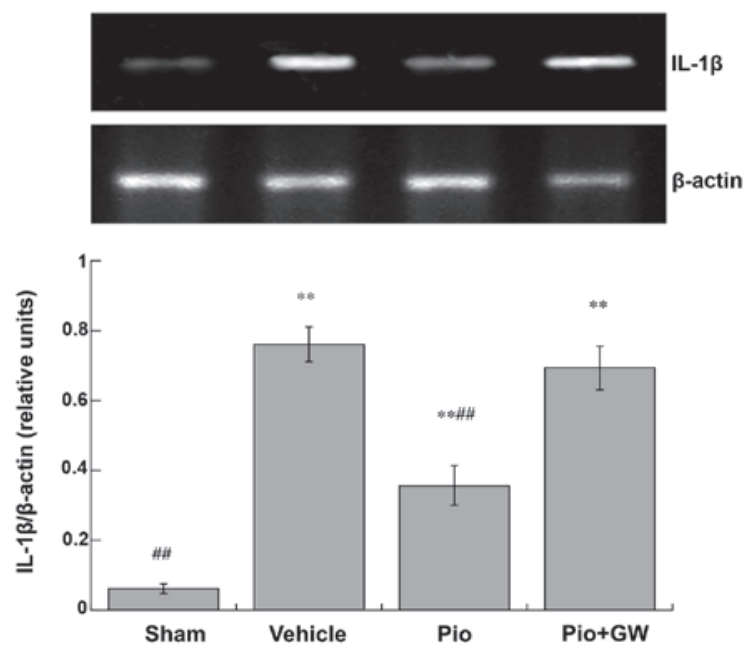

Figure 4. Spinal expression levels of IL-1 $\beta$ on day 21 post-surgery. Expression levels of IL-1 $\beta$ increased in rats after chronic constriction injury compared with sham-operated rats $\left({ }^{* *} \mathrm{P}<0.01\right)$. Pio administration attenuated the increase in the expression levels of TNF- $\alpha$ compared with the vehicle group ( $\left.{ }^{\# \#} \mathrm{P}<0.01\right)$, and this effect was reversed by $\mathrm{GW}$ co-administration. IL, interleukin; Pio, pioglitazone; GW, GW9662.

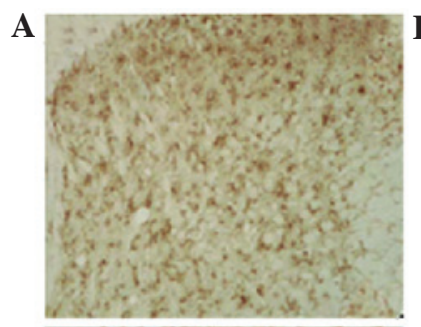

C

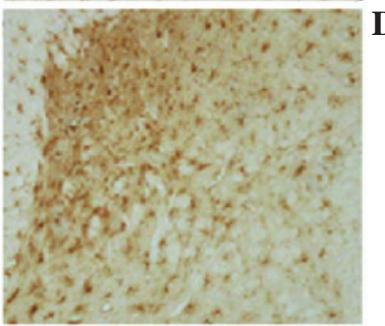

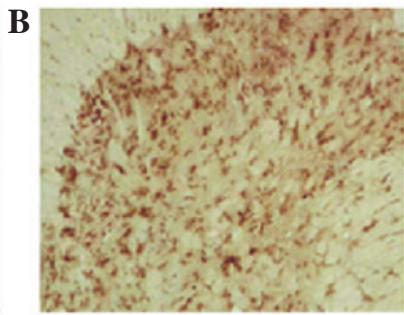

D

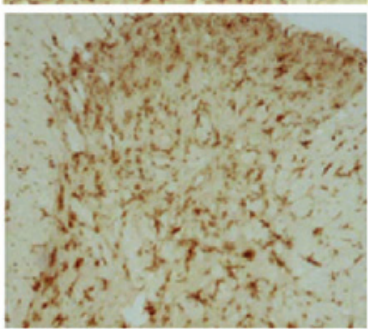

E

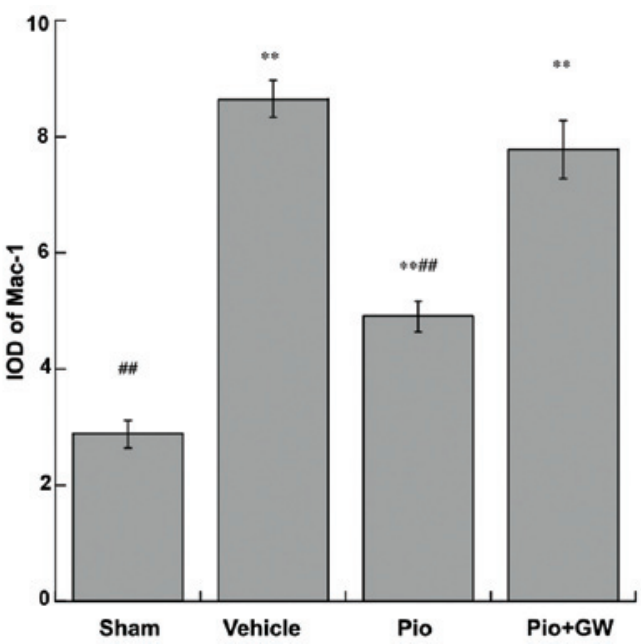

Figure 5. Mac-1 activation after CCI is suppressed by Pio 21 days after surgery. (A) Rats that received sham surgery (sham group) displayed low levels of Mac-1 immunoreactivity. (B) The vehicle group demonstrated robustly activated microcytes with intense Mac-1 staining. (C) Administration of Pio to rats with CCI led to substantial suppression of microcytic activation (Pio group), and (D) this effect was reversed by coadministration with GW (Pio + GW group). (E) Subsequent quantitative analysis. Magnification, $\mathrm{x} 200 .{ }^{* *} \mathrm{P}<0.01$ vs. the sham group; ${ }^{\# \#} \mathrm{P}<0.01$ vs. the the vehicle and Pio $+\mathrm{GW}$ groups. CCI, chronic constriction injury; GW, GW9662.

(Figs. 1 and 2). It was observed that CCI produced significant mechanical hyperalgesia and cold allodynia in the ipsilateral hind paw of rats on postoperative day 3 , and these effects persisted to postoperative day 21 . Pio $(10 \mathrm{mg} / \mathrm{kg})$ administration was able to attenuate the development of mechanical hyperalgesia and cold allodynia in rats with CCI compared with those who received the vehicle treatment on days 3,7 , 14 and 21 post-operation ( $\mathrm{P}<0.01$ for $10 \mathrm{mg} / \mathrm{kg}$ ). When coadministered with Pio, GW9662 (2 mg/kg, i.p.), an antagonist of PPAR- $\gamma$, was able to reverse the analgesic effect of Pio $(\mathrm{P}<0.01$; Figs. 1 and 2).

Production of cytokines. Expression levels of TNF- $\alpha$ (Fig. 3) and IL-1 $\beta$ (Fig. 4) in the spinal cord were significantly increased in CCI rats compared with saline-treated rats. CCI-induced neuropathic pain was associated with a significant increase in the protein expression levels of IL-1 $\beta$ and TNF- $\alpha(\mathrm{P}<0.01)$. Pio was able to significantly suppress the elevation of IL-1 $\beta$ and TNF- $\alpha$ (both $\mathrm{P}<0.01)$. However, GW9662 (2 mg/kg, i.p.) was able to reduce the decrease in IL-1 $\beta$ and TNF- $\alpha$ levels induced by Pio in the spinal cord.

Expression of glial activation markers. The expression of Mac-1 were investigated in the sciatic nerves of rats by immunohistochemical analysis (Fig. 5). Pio-treated rats exhibited a significant attenuation in Mac-1 immunoreactivity. The integral optical density of Mac-1 immunoreactive cells increased significantly $(\mathrm{P}<0.01)$ in the Pio group compared with the 

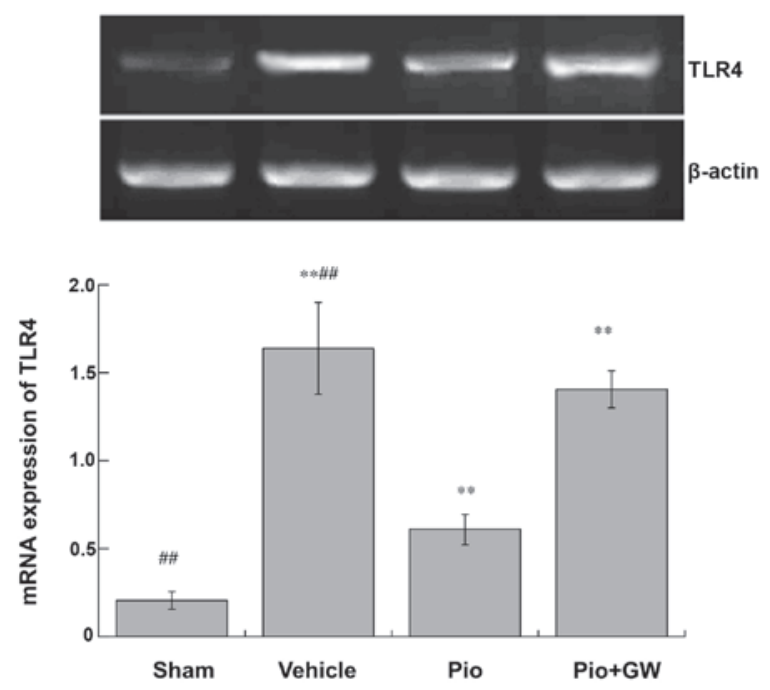

Figure 6 . Activity of TLR- 4 in the spine on day 21 post-surgery. Activity of TLR-4 increased in rats after chronic constriction injury compared with rats in the sham group $\left({ }^{* *} \mathrm{P}<0.01\right)$. Pio administration attenuated the increased activity of TLR- 4 compared with vehicle administration $\left({ }^{\# \#} \mathrm{P}<0.01\right)$, which was reversed by GW coadministration. TLR, toll-like receptor; Pio, pioglitazone; GW, GW9662.

sham group and vehicle groups, and this effect was reversed by GW9662 coadministration $(\mathrm{P}<0.01)$.

mRNA expression of TLR-4. mRNA expression levels of TLR- 4 were significantly increased in rats on postoperative day 21 in the vehicle group compared with the sham group $(\mathrm{P}<0.01)$. Pio administration significantly attenuated the increase in TLR-4 expression levels compared with vehicle administration $(\mathrm{P}<0.01)$, which was significantly reversed by GW9662 coadministration ( $\mathrm{P}<0.01$; Fig. 6).

\section{Discussion}

The present study investigated the potential therapeutic value of Pio, which is a PPAR- $\gamma$ agonist, in the treatment of neuropathic pain using a rat model of CCI. Pio was effective in reducing the incidence of the development of mechanical hyperalgesia and the upregulation of Mac-1 and cytokines, and suppressing the activity of TLR-4 in rats after CCI. GW9662 reversed the aforementioned changes produced by Pio in rats with CCI.

Neuropathic pain is characterized by hyperalgesia, allodynia and spontaneous pain. At present, available treatments for neuropathic pain are neither adequate nor effective, partially due to the fact that the underlying mechanisms are insufficiently understood. Current therapies for the treatment of peripheral neuropathic pain involve numerous drug classes, including opioids, gabapentinoids, antidepressants, antiepileptic drugs, local anesthetics and capsaicin. However, the majority of these treatments have limited efficacy or produce undesirable adverse effects (1). Thus, increasing research effort has been applied to the development of novel therapeutic targets and drugs for the treatment of neuropathic pain.

Rosiglitazone and Pio are synthetic PPAR- $\gamma$ agonists of the thiazolidinedione (TZD) class. As insulin sensitizers, TZDs remain an important pharmacotherapeutic class in the treatment of type II diabetes. Several studies have suggested that systemically administered TZD class drugs facilitate recovery from behavioral changes during neuropathic pain associated with tibial and sural nerve transection, in addition to carrageenan-induced inflammation, spared nerve injury and L5 nerve transection-induced neuropathy (21-25). The findings of the current study were consistent with the aforementioned observations that Pio attenuated the development of mechanical hyperalgesia and cold allodynia. Of greater note was the observation that the effects of Pio were successfully blocked by the coadministration of GW9662. Thus, the present study concluded that PPAR- $\gamma$ substantially contributes to the antinoceptive role of Pio, with respect to the amelioration of neuropathic pain. However, it should be noted that the administration of Pio for 3 weeks did not produce a significant effect on the glucose levels in rats in the current study, and that the glucose levels were within the normal range.

An increasing number of studies have implicated neuroimmune activation, which has been associated with glial activation and inflammatory cytokine expression following nerve injury, to be associated with the generation and maintenance of behavioral changes during neuropathic pain (26-28). In the spinal chord, activated microglia lead to hyperalgesia by releasing algesic soluble factors, including TNF- $\alpha$ and IL-1 $\beta$ (29). Proinflammatory cytokines have been hypothesized to contribute to the sensitization of the CNS, which results in lower thresholds and spontaneous ectopic neuronal firing (30). As a consequence, the deleterious escalation of a pathological glial activation ensues, and induces the expression levels of numerous factors, including cyclooxygenase-2, inducible nitric oxide (NO) synthase and substance $\mathrm{P}$ (8). Elevated levels of the aforementioned substances leads to increased nociceptive activity and thus severe and persistent neuropathic pain (31). Positive feedback loops between inflammatory mediators and glial activation, and between glia and neurons, lead to the enhancement and maintenance of neuropathic pain. Previous studies have indicated that, in glial cells, ligand-dependent activation of PPAR- $\gamma$ has an anti-inflammatory effect by suppressing the expression of various inflammatory response genes, including those encoding inducible NO synthase, TNF- $\alpha$ and IL-1 $\beta$ (32-34). As demonstrated in the present study, microglial activation, indicated by increased mRNA expression levels of the surface marker, Mac-1, led to elevated expression levels of TNF- $\alpha$ and IL-1 $\beta$ inflammatory mediators, which may, in part, account for the mechanical allodynia observed in nerve injury models of CCI (35-37). PPAR- $\gamma$ receptors are expressed on glial cells in the CNS (38) and spinal cord (39), and the present results indicated that Pio significantly decreased Mac-1 immunoreactivity and the production of TNF- $\alpha$ and IL-1 $\beta$ in the lumbar dorsal horn. Thus, we hypothesize that Pio inhibits the maintenance of neuropathic pain by decreasing microglia activity, which is the primary source of inflammatory cytokines in the dorsal horn.

It has previously been suggested that the TLR-4 signaling pathway has an important role in neuropathic pain $(40,41)$. Proinflammatory cytokines (IL-1 $\beta$, TNF- $\alpha$, IL- 6 and INF- $\gamma$ ) are released by the microglial TLR- 4 receptor, which is one of several neuron-to-glia signalling receptors. TLR-4 
is a transmembrane receptor protein with extracellular leucine-rich repeat domains and a cytoplasmic signaling domain. In the CNS, TLR-4 is expressed on microglia, and possibly astrocytes and endothelial cells; however, it is not expressed on neurons (42). Previous studies have suggested several potential mechanisms that may mediate the neuroprotective actions of Pio, including diminished inflammation, and activation of TLR, nuclear factor- $\kappa \mathrm{B}$ and antiapoptotic genes $(11,21,43)$. However, to the best of our knowledge, the current study is the first to demonstrate that Pio is able to inhibit TLR-4 expression during neuropathic pain. This was in agreement with the findings of a previous study, which reported that Pio inhibits the activation of TLR-4 in lipopolysaccharide-stimulated microglia cultures. Further studies are required to elucidate the role of various signaling pathways besides that of TLR-4 signaling in peripheral nerve injury.

In conclusion, the present study demonstrated that Pio administration had an antiallodynic effect in a rat model of neuropathic pain by inhibiting glial activation and the expression of TLR-4, which consequently inhibited the production of proinflammatory cytokines. The results concerning the protective effects of Pio on hyperalgesia, glial activation, and inflammatory response in the present study may provide a novel therapeutic strategy for the treatment of neuropathic pain.

\section{References}

1. Scholz J and Woolf CJ: The neuropathic pain triad: Neurons, immune cells and glia. Nat Neurosci 10: 1361-1368, 2007.

2. Alfonso Romero-Sandoval E and Sweitzer S: Nonneuronal central mechanisms of pain: Glia and immune response. Prog Mol Biol Transl Sci 131: 325-358, 2015.

3. Aloisi F: Immune function of microglia. Glia 36: 165-179, 2001.

4. DeLeo JA and Yezierski RP: The role of neuroinflammation and neuroimmune activation in persistent pain. Pain 90: 1-6, 2001.

5. Dong Y and Benveniste EN: Immune function of astrocytes. Glia 36: 180-190, 2001.

6. Mantyh PW, Clohisy DR, Koltzenburg M and Hunt SP: Molecular mechanisms of cancer pain. Nat Rev Cancer 2: 201-209, 2002

7. Ruohonen S, Jagodi M, Khademi M, Taskinen HS, Ojala P, Olsson T and Röyttä M: Contralateral non-operated nerve to transected rat sciatic nerve shows increased expression of IL-1beta, TGF-beta1, TNF-alpha and IL-10. J Neuroimmunol 132: 11-17, 2002.

8. Ji RR, Berta T and Nedergaard M: Glia and pain: Is chronic pain a gliopathy? Pain 154: S10-28, 2013.

9. Wolska A, Lech-Maranda E and Robak T: Toll-like receptors and their role in hematologic malignancies. Curr Mol Med 9: 324-335, 2009

10. Buchanan MM, Hutchinson M, Watkins LR and Yin H: Toll-like receptor 4 in CNS pathologies. J Neurochem 114: 13-27, 2010.

11. Park SW, Yi JH, Miranpuri G, Satriotomo I, Bowen K, Resnick DK and Vemuganti R: Thiazolidinedione class of peroxisome proliferator-activated receptor gamma agonists prevents neuronal damage, motor dysfunction, myelin loss, neuropathic pain and inflammation after spinal cord injury in adult rats. J Pharmacol Exp Ther 320: 1002-1012, 2007.

12. Zhao Y, Patzer A, Herdegen T, Gohlke P and Culman J: Activation of cerebral peroxisome proliferator-activated receptors gamma promotes neuroprotection by attenuation of neuronal cyclooxygenase-2 overexpression after focal cerebral ischemia in rats. FASEB J 20: 1162-1175, 2006.

13. Zhao X and Li LY: PPAR-alpha agonist fenofibrate induces renal CYP enzymes and reduces blood pressure and glomerular hypertrophy in Zucker diabetic fatty rats. Am J Nephrol 28: 598-606, 2008 .
14. Diab A, Hussain RZ, Lovett-Racke AE, Chavis JA, Drew PD and Racke MK: Ligands for the peroxisome proliferator-activated receptor-gamma and the retinoid $\mathrm{X}$ receptor exert additive anti-inflammatory effects on experimental autoimmune encephalomyelitis. J Neuroimmunol 148: 116-126, 2004.

15. Breidert T, Callebert J, Heneka MT, Landreth G, Launay JM and Hirsch EC: Protective action of the peroxisome proliferator-activated receptor-gamma agonist pioglitazone in a mouse model of Parkinson's disease. J Neurochem 82: 615-624, 2002.

16. Pedersen WA, McMillan PJ, Kulstad JJ, Leverenz JB, Craft S and Haynatzki GR: Rosiglitazone attenuates learning and memory deficits in $\operatorname{Tg} 2576$ Alzheimer mice. Exp Neurol 199: 265-273, 2006.

17. Heneka MT, Sastre M, Dumitrescu-Ozimek L, Hanke A, Dewachter I, Kuiperi C, O'Banion K, Klockgether T, Van Leuven F and Landreth GE: Acute treatment with the PPAR-gamma agonist pioglitazone and ibuprofen reduces glial inflammation and Abeta1-42 levels in APPV717I transgenic mice. Brain 128: 1442-1453, 2005.

18. Bennett GJ and Xie YK: A peripheral mononeuropathy in rat that produces disorders of pain sensation like those seen in man. Pain 33: 87-107, 1998.

19. Chaplan SR, Bach FW, Pogrel JW, Chung JM and Yaksh TL: Quantitative assessment of tactile allodynia in the rat paw. J Neurosci Methods 53: 55-63, 1994.

20. Kim YI, Na HS, Yoon YW, Han HC, Ko KH and Hong SK: NMDA receptors are important for both mechanical and thermal allodynia from peripheral nerve injury in rats. Neuroreport 8: 2149-2153, 1997.

21. Jain V, Jaggi AS and Singh N: Ameliorative potential of rosiglitazone in tibial and sural nerve transection-induced painful neuropathy in rats. Pharmacol Res 59: 385-392, 2009.

22. Jia H, Zhu S, Ji Q, Hui K, Duan M, Xu J and Li W: Repeated administration of pioglitazone attenuates development of hyperalgesia in a rat model of neuropathic pain. Exp Clin Psychopharmacol 18: 359-365, 2010.

23. Maeda T, Kiguchi N, Kobayashi Y, Ozaki M and Kishioka S: Pioglitazone attenuates tactile allodynia and thermal hyperalgesia in mice subjected to peripheral nerve injury. J Pharmacol Sci 108: 341-347, 2008.

24. Takahashi Y, Hasegawa-Moriyama M, Sakurai T and Inada E: The macrophage-mediated effects of the peroxisome proliferator-activated receptor-gamma agonist rosiglitazone attenuate tactile allodynia in the early phase of neuropathic pain development. Anesth Analg 113: 398-404, 2011.

25. Churi SB, Abdel-Aleem OS, Tumber KK, Scuderi-Porter H and Taylor BK: Intrathecal rosiglitazone acts at peroxisome proliferator-activated receptor-gamma to rapidly inhibit neuropathic pain in rats. J Pain 9: 639-649, 2008.

26. Zhang ZJ, Cao DL, Zhang X, Ji RR and Gao YJ: Chemokine contribution to neuropathic pain: Respective induction of CXCL1 and CXCR2 in spinal cord astrocytes and neurons. Pain 154: 2185-2197, 2013.

27. Akimoto N, Ifuku M, Mori Y and Noda M: Effects of chemokine (C-C motif) ligand 1 on microglial function. Biochem Biophys Res Commun 436: 455-461, 2013.

28. Clark AK, Old EA and Malcangio M: Neuropathic pain and cytokines: Current perspectives. J Pain Res 6: 803-814, 2013.

29. Ji RR and Suter MR: P38 MAPK, microglial signaling, and neuropathic pain. Mol Pain 3: 33, 2007.

30. Moalem G and Tracey DJ: Immune and inflammatory mechanisms in neuropathic pain. Brain Res Rev 51: 240-264, 2006.

31. Inoue M, Yamada $\mathrm{T}$ and Ueda $\mathrm{H}$ : Low dose of kyotorphin (tyrosine-arginine) induces nociceptive responses through a substance P release from nociceptor endings. Brain Res Mol Brain Res 69: 302-305, 1999.

32. Zingarelli B, Sheehan M, Hake PW, O'Connor M, Denenberg A and Cook JA: Peroxisome proliferator activator receptor-gamma ligands, 15-deoxy-Delta(12,14)-prostaglandin J2 and ciglitazone, reduce systemic inflammation in polymicrobial sepsis by modulation of signal transduction pathways. J Immunol 171: 6827-6837, 2003

33. Fuenzalida K, Quintanilla R, Ramos P, Piderit D, Fuentealba RA, Martinez G, Inestrosa NC and Bronfman M: Peroxisome proliferator-activated receptor gamma up-regulates the Bcl-2 anti-apoptotic protein in neurons and induces mitochondrial stabilization and protection against oxidative stress and apoptosis. J Biol Chem 282: 37006-37015, 2007. 
34. Bernardo A, Ajmone-Cat MA, Gasparini L, Ongini E and Minghetti L: Nuclear receptor peroxisome proliferator-activated receptor-gamma is activated in rat microglial cells by the anti-inflammatory drug HCT1026, a derivative of flurbiprofen. J Neurochem 92: 895-903, 2005.

35. Watkins LR, Milligan ED and Maier SF: Glial activation: A driving force for pathological pain. Trends Neurosci 24: 450-455, 2001.

36. Luna-Medina R, Cortes-Canteli M, Alonso M, Santos A, Martínez A and Perez-Castillo A: Regulation of inflammatory response in neural cells in vitro by thiadiazolidinones derivatives through peroxisome proliferator-activated receptor gamma activation. J Biol Chem 280: 21453-21462, 2005.

37. Chen Y, Willcockson HH and Valtschanoff JG: Influence of the vanilloid receptor TRPV1 on the activation of spinal cord glia in mouse models of pain. Exp Neurol 220: 383-390, 2009.

38. Moreno S, Farioli-Vecchioli S and Cerù MP: Immunolocalization of peroxisome proliferator-activated receptors and retinoid $X$ receptors in the adult rat CNS. Neuroscience 123: $131-145,2004$
39. Diab A, Deng C, Smith JD, Hussain RZ, Phanavanh B, Lovett-Racke AE, Drew PD and Racke MK: Peroxisome proliferator-activated receptor-gamma agonist 15-deoxy-Delta $(12,14)$-prostaglandin $\mathrm{J} 2$ ameliorates experimental autoimmune encephalomyelitis. J Immunol 168: 2508-2515, 2002.

40. Hutchinson MR, Zhang Y, Brown K, Coats BD, Shridhar M, Sholar PW, Patel SJ, Crysdale NY, Harrison JA, Maier SF, et al: Non-stereoselective reversal of neuropathic pain by naloxone and naltrexone: Involvement of toll-like receptor 4 (TLR4). Eur J Neurosci 28: 20-29, 2008

41. Cao L, Tanga FY and DeLeo JA: The contributing role of CD14 in toll-like receptor 4 dependent neuropathic pain. Neuroscience 158: 896-903, 2009.

42. Miyake K: Innate immune sensing of pathogens and danger signals by cell surface Toll-like receptors. Semin Immunol 19: 3-10, 2007.

43. Gurley C, Nichols J, Liu S, Phulwani NK, Esen N and Kielian T: Microglia and Astrocyte Activation by Toll-Like Receptor Ligands: Modulation by PPAR-gamma Agonists. PPAR Res 2008: 453120, 2008. 